\title{
Correction to: Robust fuzzy control for fractional-order systems with estimated fraction-order
}

\author{
Mohammad Hosein Sabzalian • \\ Ardashir Mohammadzadeh • Shuyi Lin • \\ Weidong Zhang $\mathbb{D}$
}

Published online: 21 October 2019

(C) Springer Nature B.V. 2019

\section{Correction to:}

\section{Nonlinear Dyn}

https://doi.org/10.1007/s11071-019-05217-w

The correct spelling of the 2nd author's surname is Mohammadzadeh.

The original article has been corrected.

The online version of the original article can be found under https://doi.org/10.1007/s11071-019-05217-w.

M. H. Sabzalian · S. Lin · W. Zhang ( $\varangle)$

Department of Automation, Shanghai Jiaotong University, Shanghai 200240, People's Republic of China e-mail:wdzhang@sjtu.edu.cn

A. Mohammadzadeh

Department of Electrical Engineering, University of

Bonab, Bonab, Iran

S. Lin

School of Industrial Engineering, Purdue University, West Lafayette, IN 47906, USA

Publisher's Note Springer Nature remains neutral with regard to jurisdictional claims in published maps and institutional affiliations. 